\title{
PENERAPAN PEMBELAJARAN AKUNTANSI BERBASIS APLIKASI PADA MAHASISWA TEKNIK INFORMATIKA POLITEKNIK NEGERI BENGKALIS
}

\author{
Oleh: Suharyono \\ suharyono@polbeng.ac.id \\ (Program Studi D4 Akuntansi Keuangan Publik, Politeknik Negeri Bengkalis)
}

\begin{abstract}
Abstrak-Akuntansi bukanlah seni yang dapat dikuasai dengan mudah. Dalam melakukan transfer kompetensi dibutuhkan seni yang spesial, khususnya bagi mahasiswa yang bukan dari Fakultas Ekonomi dan Bisnis. Penelitian ini dilakukan untuk mengukur kemampuan mahasiswa dari hasil belajar mata kuliah akuntansi. Metode penelitian ini dapat dikategorikan penelitian kuantitatif. Uji MannWhiteney dipilih sebagai alternatif dalam pengolahan data. Jumlah populasi dalam penelitian ini adalah 57 orang mahasiswa semester 1 Program Studi D3 Teknik Informatika kelas A dan kelas B selama satu semester. Hasilnya adalah kemampuan mahasiswa mengoperasikan aplikasi akuntansi antara kelas $A$ dan $B$ secara rata-rata adalah sama. Artinya mahasiswa mampu membuat file perusahaan, melakukan pengaturan daftar, menginput saldo awal, mencatat transaksi, dan menyajikan laporan keuangan.
\end{abstract}

Kata Kunci : Akuntansi, Seni, Kemampuan, Teknik, Informatika.

Abstract-Accounting is not an art that can be mastered easily. In transferring competence, special arts are needed, especially for students who are not from the Faculty of Economics and Business. This research was conducted to measure the student's ability from the learning outcomes of accounting courses. The MannWhiteney test was chosen as an alternative in data processing. The total population in this study were 57 semester 1 students of the Informatics Engineering D3 Study Program class $A$ and class $B$ for one semester. The result is that the students' ability to operate accounting applications between classes $A$ and $B$ is on average the same. This means that students are able to create company files, manage lists, enter initial balances, record transactions, and present financial reports.

Keywords: Accounting, Arts, Skills, Engineering, Informatics.

\section{PENDAHULUAN}

Akuntansi merupakan salah satu seni yang tergolong khusus dan unik dalam mengumpulkan, memproses dan menyajikan seluruh transaksi dan kejadian keuangan. Program Studi D3 Teknik

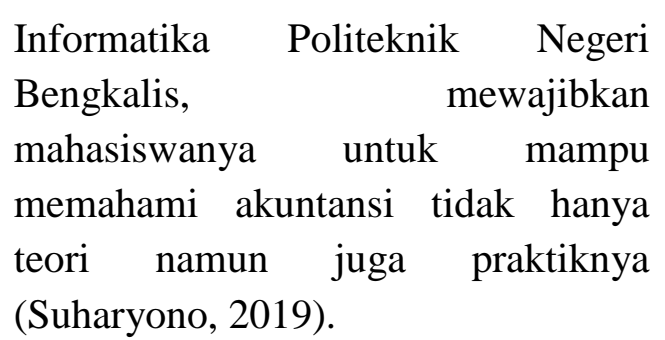


Dalam praktiknya, akuntansi dan teknik informatika, adalah dua departemen yang saling membutuhkan dan tak dapat dipisahkan. Perkembangan teknologi digital yang pesat, mendorong terjadinya perubahan peran akuntansi dengan cara yang sebelumnya tidak pernah terpikirkan.

Untuk mendukung peran akuntan, maka mahasiswa teknik informatika harus mampu memahami tentang akuntansi sebagai penghubung dalam memanfaatkan perkembangan teknologi otomatisasi baik melalui bots atau perangkat lunak lainnya (Suharyono, 2021). Dengan demikian alat tersebut dapat mengubah pekerjaan manual menjadi otomatis dan membuat pemrograman menjadi lebih ringan (Suharyono, 2021).

Selain itu, media berbasis teknologi informasi yang mulai dikembangkan adalah aplikasi pembelajaran (Akmal, 2018). Penelitian ini bertujuan untuk mengetahui tingkat pemahaman mahasiswa D3 Teknik Informatika dalam bidang akuntansi melalui pembelajaran berbasis aplikasi.

Menurut Akmal (2018) aplikasi pembelajaran android yang dapat di unduh melalui telepon pintar dapat digunakan sebagai media pengenalan yang efektif. Selain memudahkan penggunaan, android merupakan alat yang umum dimiliki pelajar.

Menurut Handayani (2019), mengembangkan media pembelajaran berbasis aplikasi dapat mengatasi permasalahan yang tepat di masa pandemic. Dengan aplikasi yang tersedia, dapat memudahkan mahasiswa dalam mengakses dengan perangkat yang dimilikinya (Rosmida, 2017).

Untuk mempelajari akuntansi, telah banyak aplikasi-aplikasi pendukung yang dapat digunakan baik secara gratis maupun berbayar (Suharyono, 2021). Beberapa aplikasi yang bisa digunakan antara lain SI APIK, MYOB, Zahir, Accurate, Aplikasi Android Akuntansi UKM, dan lain sebagainya (Suharyono, 2019).

\section{METODE PENELITIAN}

Metode penelitian ini dapat dikategorikan penelitian kuantitatif. Dalam penelitian kuantitatif ini peneliti akan mengunakan angka untuk dianalisa outputnya berdasarkan hasil pengujian statistik.

Data primer dipilih dalam penelitian ini, yang merupakan skor akhir yang diperoleh mahasiswa di akhir perkuliahan akuntansi. Skor ini diperoleh dari hasil akhir atas pengujian beberapa soal dengan beberapa aplikasi akuntansi, seperti hasil pengujian dengan menggunakan aplikasi MYOB, SI APIK, dan aplikasi android Akuntansi UKM (Suharyono, 2017).

Populasi penelitian sebanyak 57 orang mahasiswa dengan rincian kelas A sebanyak 28 orang dan kelas B sebanyak 29 orang. Seluruhnya 
adalah mahasiswa aktif yang telah mengikuti ujian praktikum akuntansi.

Variabel yang diteliti hanya satu. Variabelnya adalah tingkat kemampuan akuntansi yang dimiliki mahasiswa D3 Teknik Informatika.
Penelitian ini menggunakan alat uji Mann-Whiteney. Pengujian memanfaatkan aplikasi SPSS v22.

Desain penelitian dapat dilihat pada gambar dibawah ini.

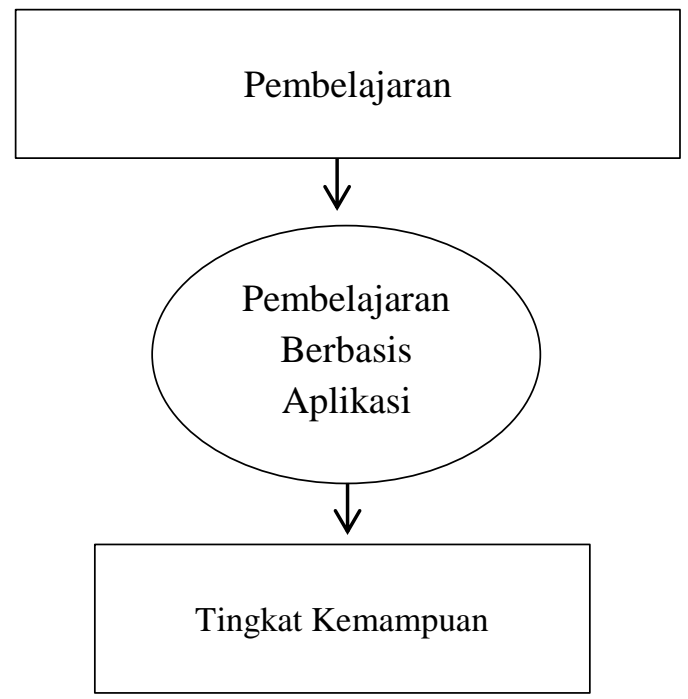

Gambar 1. Desain Penelitian (Sumber: Data Primer yang diolah, 2021)

\section{HASIL DAN PEMBAHASAN}

Penelitian ini untuk melihat tingkat kemampuan mahasiswa Program Studi D3 Teknik
Informatika Politeknik Negeri Bengkalis semester 1. Tabel 1 dibawah ini menyajikan output data secara deskriptif.

Tabel 1. Deskriptif

\begin{tabular}{|c|c|c|c|c|c|}
\hline No & Kelas & Rata-rata & Skor minimal & Skor Maksimal & Nilai tengah \\
\hline 1 & A & 75,3 & 65 & 100 & 75 \\
\hline 2 & B & 74,5 & 65 & 100 & 70 \\
\hline
\end{tabular}

Sumber: Data Primer yang diolah, 2021

Berdasarkan Tabel 2, rata-rata nilai akhir mata kuliah akuntansi dengan pembelajaran berbasis aplikasi yang diperoleh oleh kelas A adalah 75,3 sedangkan rata-rata nilai akhir yang diperoleh kelas B adalah 74,5. Dapat disimpulkan bahwa rata- rata nilai akhir untuk kelas A lebih tinggi dibanding dengan rata-rata nilai akhir kelas B.

Melalui tabel diatas juga dapat dilihat bahwa tingkat kemampuan dan pemahaman akuntansi mahasiswa D3 Teknik Informatika bervariasi, 
dengan nilai minimal 65 dan maksimal 100. Ini menunjukkan secara rata-rata kemampuan mahasiswa adalah baik.

\section{Uji Normalitas}

Output uji normalitas akan menentukan alat uji hipotesis, apakah menggunakan statistik parametrik atau nonparametrik (Mule, 2019). Output pengujian normalitas data disajikan pada Tabel 2.

Tabel 2. Normalitas

\begin{tabular}{|c|c|c|c|}
\hline No. & Kelas & Sig & Ketarangan \\
\hline 1 & A & 0,000 & Tidak Normal \\
\hline 2 & B & 0,000 & Tidak Normal \\
\hline
\end{tabular}

Sumber: Data Primer yang diolah, 2021

Hasil uji normalitas menunjukkan bahwa seluruh data berdistribusi tidak normal. Untuk pengujian hipotesis dalam penelitian ini akan digunakan uji mannwhiteney.

\section{Tingkat Kemampuan Mahasiswa Teknik Informatika dalam bidang Akuntansi}

Setelah proses pembelajaran akuntansi berbasis aplikasi selesai, dilanjutkan dengan evaluasi untuk mendapatkan nilai akhir perkuliahan. Nilai tersebut ditabulasi untuk diolah dan dianalisis secara statistik. Hasil pengujian Mann Whitney telah diperoleh dan disajikan di dalam tabel dibawah ini.

Tabel 3. Mann-Whiteney

\begin{tabular}{|c|c|c|c|}
\hline No & Variabel & Sig & Keterangan \\
\hline 1 & Hasil Belajar & 0,599 & Tidak Berbeda \\
\hline
\end{tabular}

Sumber: Data Primer yang diolah, 2021

Hasil pengujian perbandingan tingkat kemampuan akuntansi melalui pembelajaran berbasis aplikasi antara kelas A dengan kelas B adalah $59,9 \%$. Nilai signifikansi ini menunjukkan lebih tinggi dibanding $p$ value 5\%. Ini artinya tingkat kemampuan akuntansi antara keduanya tidak memiliki perbedaan.

Secara umum, mahasiswa telah mampu menjalankan atau mengoperasikan aplikasi akuntansi dengan baik. Dengan nilai minimal 65 poin. Artinya mahasiswa telah memiliki kemampuan untuk membuat data perusahaan, membuat id/password, membuka file perusahaan, membuat akun, menghapus akun, mengedit akun, membuat daftar pajak, membuat daftar persediaan, membuat daftar pekerjaan, membuat daftar kartu 
pelanggan/pemasok, membuat daftar kategori, mengisi saldo awal neraca, mengisi saldo piutang/utang, mengisi saldo persediaan awal, menginput pembelian, menginput penjualan, return, mengiput diskon, menginput penerimaan/pengeluaran kas, membuat jurnal penyesuaian, melakukan rekonsiliasi bank. Sedangkan beberapa mahasiswa bahkan telah berhasil mendapatkan skor sempurna dan memiliki kemampuan untuk menggunakan menu recurring, menyajikan laporan keuangan, mengedit atau menghapus transaksi, mengatur template laporan keuangan, dan melakukan bekup file.

\section{KESIMPULAN}

Penelitian ini dilakukan untuk mengukur kemampuan mahasiswa dari hasil belajar mata kuliah akuntansi. Uji Mann-Whiteney dipilih sebagai alternatif dalam pengolahan data. Jumlah populasi dalam penelitian ini adalah 57 orang mahasiswa semester 1 Program Studi D3 Teknik Informatika kelas A dan kelas B selama satu semester. Hasilnya adalah kemampuan mahasiswa mengoperasikan aplikasi akuntansi antara kelas A dan B sebesar $59,9 \%$ yang artinya secara rata-rata adalah sama. Artinya mahasiswa mampu membuat file perusahaan, melakukan pengaturan daftar, menginput saldo awal, mencatat transaksi, dan menyajikan laporan keuangan.
Penelitian ini hanyalah mengukur satu metode dalam pembelajaran akuntansi untuk mahasiswa Teknik Informatika. Kedepan diharapkan bisa dilakukan analisis dengan membandingkan metode-metode lain yang diterapkan dalam proses pembelajaran akuntansi.

\section{DAFTAR PUSTAKA}

Akmal, H., \& Susanto, H. (2018). Efektivitas Penggunaan Aplikasi Pembelajaran Berbasis Mobile Smartphone Sebagai Media Pengenalan Sejarah Lokal Masa Revolusi Fisik Di Kalimantan Selatan Pada Siswa Sekolah Menengah Atas. Jurnal Historia, 6(2), 197-206.

Handayani, A., Husni, N. L., Soim, S., Rumiasih, R., Sitompul, C. R., Nurdin, A., \& Suroso, S. (2019). Pengembangan materi pembelajaran berbasis aplikasi. SnaptekmaS, 1(1).

Mule, Y. (2019). Comparative Analysis of Students Learning Achievement in The Advanced Public Sector Accounting. Jurnal AKSI (Akuntansi dan Sistem Informasi), 4(2).

Rosmida, R., \& Suharyono, S. (2017). Pengaruh Kualitas Pengajaran, Faktor Internal dan Faktor Eskternal Secara Simultan Terhadap Prestasi Belajar Mahasiswa pada Mata Kuliah Pengantar Akuntansi. Jurnal Akuntansi Keuangan dan Bisnis, 10(2), 17.

Suharyono, S., \& Widodo, T. (2017). Analisis Hasil Belajar Mahasiswa dalam Mata Kuliah 
Komputer Akuntansi. Inovbiz: Jurnal Inovasi Bisnis, 5(1), 2935.

Suharyono, S. (2019). Pengaruh Myob Test Clinic Terhadap Kompetensi Mahasiswa. Jurnal Analisa Akuntansi dan Perpajakan, 2(2).

Suharyono, S. (2019).

Profesionalisme Mahasiswa Akuntansi dan Mahasiswa Administrasi Bisnis dalam Mengoperasikan Aplikasi Komputer Akuntansi. Jurnal Akuntansi Kontemporer, 11(2), 85-92.

Suharyono, S. (2021). Evaluasi Pembelajaran Mata Kuliah Audit Pada Mahasiswa Politeknik Negeri Bengkalis. JEKPEND: Jurnal Ekonomi dan Pendidikan, 4(1), 48-55.

Suharyono, S. (2021). Penerapan The Law Of Repetition Dalam Pembelajaran Pengantar Akuntansi. Jurnal Neraca: Jurnal Pendidikan dan Ilmu Ekonomi Akuntansi, 5(1), 5769.

Suharyono, S. (2021). Penerapan

Software Akuntansi Pada Umkm Ferolas. Jurnal Akuntansi dan Keuangan, 10(1), 1-6. 